\title{
Conductivity/activation energy relationships for cement-based materials undergoing cyclic thermal excursions
}

\author{
W. J. McCarter · G. Starrs · T. M. Chrisp • \\ P. A. M. Basheer • S. V. Nanukuttan • \\ S. Srinivasan
}

Received: 19 June 2014/ Accepted: 13 October 2014/Published online: 21 October 2014

(C) Springer Science+Business Media New York 2014

\begin{abstract}
The electrical conductivity of a range of concrete mixes, with and without supplementary cementitious materials (SCM), is studied through multiple cycles of heating and cooling over the extended temperature range $-30 /+70{ }^{\circ} \mathrm{C}$. When presented in an Arrhenius format, the experimental results display hysteresis effects at the lowtemperature end of the thermal cycle and, in those concretes containing supplementary cementitious materials at higher water/binder ratios, hysteresis effects were evident over the entire temperature range becoming more discernible with increasing number of thermal cycles. The depression in both the freezing and thawing point could be clearly identified and was used to estimate pore-neck and pore-cavity radii. A simplified approach is presented to evaluate the volumetric ratio of frozen pore water in terms of conductivity measurements. The results also show that the conductivity and activation energy of the concrete specimens were related to the water/binder ratio, type of SCM, physical state of the pore water and the thermal cycling regime.
\end{abstract}

W. J. McCarter $(\varangle) \cdot$ G. Starrs · T. M. Chrisp

School of Energy, Geoscience, Infrastructure and Society,

Institute for Infrastructure and Environment, Heriot Watt

University, Edinburgh EH14 4AS, Scotland, UK

e-mail: w.j.mccarter@hw.ac.uk

P. A. M. Basheer

School of Civil Engineering, University of Leeds, Leeds LS2 9JT, UK

S. V. Nanukuttan · S. Srinivasan

School of Planning, Architecture and Civil Engineering, Queen's

University, Belfast BT7 1NN, N. Ireland, UK

\section{Introduction}

The durability of concrete depends primarily on the ease (or difficulty) with which fluids in the form of liquid (water), gas (carbon dioxide, oxygen) or dissolved ions (chlorides, sulphates) can move through the hardened material [1]. In this respect, transport properties such as diffusion, permeability and absorption are key factors in deterioration processes such as, for example, corrosion of the steel reinforcement resulting from chloride ingress and carbonation, sulphate attack and freeze-thaw damage. It is evident that concrete durability is intimately linked to the microporous nature of the cementitious binder hence pore size, pore-size distribution, pore connectivity and pore constriction all play an important role in the long-term performance of concrete structures.

Regarding freeze/thaw action, the freezing point of the pore water and the volumetric ratio of frozen water formed within the pores are key parameters governing the mechanical behaviour of concrete upon frost action [2-4]. In attempting to assess the potential damage caused by freeze-thaw action and the frost vulnerability of concrete, the ability to monitor ice formation within a particular cementitious material is critical and a number of techniques, both direct and indirect, have now been developed in this respect. Freezing and ice formation within the pore network of cement-based systems have been traditionally studied using low-temperature calorimetry [5-8]. Other techniques include thermoporometry (TPM) and cryoporometry [9-12]; both these methods exploit the dependence of freezing temperature on pore size, whereas cryoporometry detects the phase transition using nuclear magnetic resonance imaging, TPM is undertaken using differential scanning calorimetry and measuring heat flux due to ice penetration in cement pores. Neutron 
diffraction [13, 14], ultrasonic and dielectric techniques [3] have also been developed to study ice formation in cement paste. With many investigative techniques, specimens tend to be confined be relatively small samples of cement-pastes although low-temperature calorimetry has been applied to study ice formation in high-strength concrete [7].

In this paper, electrical conductivity measurements are used to study the response of concretes subjected to cyclic thermal excursions within the extended temperature range -30 to $+70{ }^{\circ} \mathrm{C}$. Studies have been reported on the variation in electrical impedance and resistivity of relatively young, cement pastes taken within the range $-80 /+20{ }^{\circ} \mathrm{C}$ [15-19]; in addition, electrical measurements have also been used to study freeze-thaw damage in a Portland cement mortar within the temperature range $-20 /+50{ }^{\circ} \mathrm{C}$ [20] and ice formation in concrete in the range $-20 /+0{ }^{\circ} \mathrm{C}$ [2]. Work to date indicates that changes in the electrical properties of cement-based materials occur on freezing and thawing which reflects both the amount of frozen pore water and mobility of the pore water. It has been suggested that this technique could form the basis for development as a durability test [16]. In civil engineering construction, however, it is concretes (i.e. cement-paste with fine and coarse aggregate particles) which are used and, as yet, there has been no systematic study on the electrical properties and activation energy of concretes exposed to cyclic heating and cooling, with concretes complying with current codes and standards. As electrical conduction takes place primarily through the cement-paste, the addition of aggregate will change the electrical properties of the composite material and therefore cannot be ignored. In addition, the increasing use of supplementary cementitious materials (SCM) such as fly ash and ground granulated blast-furnace slag as a partial replacement for Portland cement and the use of low water-binder ratios warrant investigation.

A detailed study is presented on the electrical conductivity of a wide range of concrete mixes, tested over multiple cycles of heating and cooling, with the cementitious binders comprising Portland cement and Portland cement blended with SCM's. The conductivity/temperature response is presented in an Arrhenius format thereby allowing evaluation of the activation energy for electrical conduction processes. As electrical conduction through concrete is, essentially, electrolytic in nature, changes in conductivity will reflect changes in the conduction processes which will, in turn, be related to the filamentary nature of the capillary pore network, the percolated porosity, the physical state of the pore water and microstructural changes/damage.

\section{Experimental programme}

Materials and sample preparation

The concrete mixes used within the experimental programme are presented in Table 1 . The cementitious materials comprised Portland cement (PC) clinker, CEM I 52.5N to EN197-1 [21]; CEM I cement blended with ground granulated blast-furnace slag (GGBS) to EN15167-1 [22]; and CEM I cement blended with a low-lime fly ash (FA) to EN450-1 [23]. The oxide analysis of the PC, FA and GGBS is presented in Table 2. Crushed granite aggregate, both coarse and fine, was used throughout together with a mid-range water reducer/plasticiser (SikaPlast 15RM) conforming to EN934-2 [24]. The PC and SCM's were combined at the concrete mixer. The mixes in Table 1 are such that, when considered in terms of binder content, binder composition and strength class would satisfy the requirements specified in BS 8500-1 [25] to resist environmental exposure classes XF (exposure to freezing and thawing) for an intended working life of 'both at least 50 years and at least 100 years'. However, when the water-binder $(\mathrm{w} / \mathrm{b})$ ratio is considered, only those concretes with $w / b=0.35$ would satisfy all compositional requirements to resist XF exposure class. (Note: the binder is the mass of PC plus SCM, if present).

Samples were cast as $15 \times 15 \times 15 \mathrm{~cm}$ cubes with a total of three samples cast for each mix on Table 1 together with six, $10 \times 10 \times 10 \mathrm{~cm}$ cubes for compressive strength testing. Samples were submerged in a curing tank $\left(20 \pm 2{ }^{\circ} \mathrm{C}\right)$ until required; 28 and 180-day compressive strengths are presented in Table 1 and denoted, respectively, $F_{28}$ and $F_{180}$.

\section{Electrical measurements and data acquisition}

A pair of electrodes was positioned centrally within each $15 \mathrm{~cm}$ cube at the time of casting which ensured intimate contact between the electrodes and the surrounding concrete. Each electrode comprised a $0.2 \mathrm{~cm}$ diameter stainless steel rod (approximately $10 \mathrm{~cm}$ in length); the rod was sleeved with heat shrink insulation to expose a $1.5 \mathrm{~cm}$ tip with the centre-to-centre spacing between the electrodes being $2.5 \mathrm{~cm}$; this spacing was adopted with due consideration being given to the maximum aggregate size, minimizing thermal gradients between the electrodes and reducing the influence of boundary effects at the cube surfaces (e.g. possible moisture loss). A thermistor was attached to one of the electrodes to allow the temperature to be recorded in the vicinity of electrical measurements. This is shown schematically in Fig. 1a. The electrical resistance of the concrete between the electrode pair was obtained employing a two-point technique using signal 
Table 1 Summary of concrete mixes

\begin{tabular}{|c|c|c|c|c|c|c|c|c|c|c|}
\hline Mix designation & $\mathrm{w} / \mathrm{b}$ & $\begin{array}{l}\text { CEM I } \\
\left(\mathrm{kg} / \mathrm{m}^{3}\right)\end{array}$ & $\begin{array}{l}\text { GGBS } \\
\left(\mathrm{kg} / \mathrm{m}^{3}\right)\end{array}$ & $\begin{array}{l}\mathrm{FA} \\
\mathrm{kg} / \mathrm{m}^{3}\end{array}$ & $\begin{array}{l}20 \mathrm{~mm} \\
\mathrm{~kg} / \mathrm{m}^{3}\end{array}$ & $\begin{array}{l}10 \mathrm{~mm} \\
\mathrm{~kg} / \mathrm{m}^{3}\end{array}$ & $\begin{array}{l}\text { Fine }(<4 \mathrm{~mm}) \\
\left(\mathrm{kg} / \mathrm{m}^{3}\right)\end{array}$ & $\begin{array}{l}\mathrm{Pl} \\
1 / \mathrm{m}^{3}\end{array}$ & $\begin{array}{l}\mathrm{F}_{28} \\
(\mathrm{MPa})\end{array}$ & $\begin{array}{l}\mathrm{F}_{180} \\
(\mathrm{MPa})\end{array}$ \\
\hline \multirow[t]{2}{*}{$\mathrm{PC}$} & 0.35 & 378 & - & - & 787 & 393 & 787 & 5.15 & 79 & 88 \\
\hline & 0.65 & 263 & - & - & 790 & 395 & 790 & - & 39 & 46 \\
\hline \multirow[t]{2}{*}{ PC/GGBS } & 0.35 & 245 & 132 & - & 784 & 392 & 784 & 5.13 & 81 & 89 \\
\hline & 0.65 & 171 & 92 & - & 788 & 394 & 788 & - & 35 & 45 \\
\hline \multirow[t]{2}{*}{$\mathrm{PC} / \mathrm{FA}$} & 0.35 & 242 & - & 130 & 773 & 386 & 773 & 5.06 & 65 & 81 \\
\hline & 0.65 & 169 & - & 91 & 780 & 390 & 780 & - & 24 & 38 \\
\hline
\end{tabular}

$w / b$ water/binder ratio, $P l$ plasticiser, $F_{28}$ and $F_{180}=28$-day and 180 -day compressive strength respectively

Table 2 Oxide analysis of cementitious materials

$+=$ not determined

amplitude of $350 \mathrm{mV}$ at a frequency of $1 \mathrm{kHz}$. This frequency was optimised from a priori experiments using multi-frequency measurements (impedance spectroscopy) to ensure electrode polarization effects were reduced to a minimum [26]. Specimens were contained in an environmental chamber with cabling from the cubes ducted out through a small porthole in the side of the chamber and connected to a multiplexing unit to log electrical resistance and temperature. Measurements were recorded every $5 \mathrm{~min}$ over the entire test period.

Electrical measurements are presented as conductivity (denoted, $\sigma$ in Siemens $/ \mathrm{cm}, \mathrm{S} / \mathrm{cm}$ ). The bulk conductivity, $\sigma$, of a prismatic sample of length $L(\mathrm{~cm})$ and cross-sectional area $A\left(\mathrm{~cm}^{2}\right)$, is given by,

$\sigma=\left(\frac{L}{R A}\right)(\mathrm{S} / \mathrm{cm})$

where $R$ is the measured resistance (in ohms). As the electrical field between the tips of the electrode pair embedded within a cube is non-uniform, the electrode array required calibration so that the measured resistance could be converted to conductivity. The geometrical parameter $L / A$ in Eq. (1) was evaluated by obtaining the conductivity of the concrete specimens from a 4-point measurement technique using an Agilent 4263B LCR metre at a frequency of $1 \mathrm{kHz}$. In this method, the embedded electrodes within the $15 \mathrm{~cm}$ cubes served as the voltage (sensing) electrodes with externally applied stainless steel plates serving as the current (source) electrodes (see Fig. 1b). The concrete conductivity was obtained using the method presented in [27]. The slope of the plot of concrete conductivity obtained from the 4-point method against conductance ( $1 / R$ in Siemens, $S$ ) measured across the electrode pair using the two-point method, obtains the calibration factor for the electrode pair. The data for all the concrete mixes on Table 1 are presented in Fig. 2a with the calibration factor being $0.223 \mathrm{~cm}^{-1} ; x$ and $y$ error bars represent one standard deviation and in those cases where the error bar appears missing, the data markers are larger than the error bar. This procedure was undertaken at $20{ }^{\circ} \mathrm{C}$ and prior to subjecting the cubes to temperature cycling. The measured resistance, $\mathrm{R}$ (in ohm, $\Omega$ ) across the electrode pair was then converted to conductivity, $\sigma$ (in $\mathrm{S} / \mathrm{cm}$ ), through the relationship,

$\sigma=\left(\frac{0.223}{R}\right)(\mathrm{S} / \mathrm{cm})$

Thermal cycling regime

On removal from the curing tank at approximately 12 months, the samples were surface dried and then tightly wrapped with several layers of cling film with all edges firmly sealed with duct tape. At this age, the change in conductivity due to hydration is reduced to a minimum [28]; furthermore, it is only at such longer time scales that the influence of the FA and GGBS on pore structure becomes evident. The cubes were placed in an environmental chamber at an initial temperature of $20{ }^{\circ} \mathrm{C}$ and taken through the following temperature regime:

(i) temperature reduced from 20 to $-30{ }^{\circ} \mathrm{C}$ at a rate of $6{ }^{\circ} \mathrm{C} / \mathrm{h}$;

(ii) isothermal hold for $4 \mathrm{~h}$ to allow interior of sample to achieve thermal equilibrium with the chamber;

(iii) temperature increased to $+70{ }^{\circ} \mathrm{C}$ at a rate of $6{ }^{\circ} \mathrm{C} / \mathrm{h}$;

(iv) isothermal hold for $4 \mathrm{~h}$ to allow thermal equilibrium; 


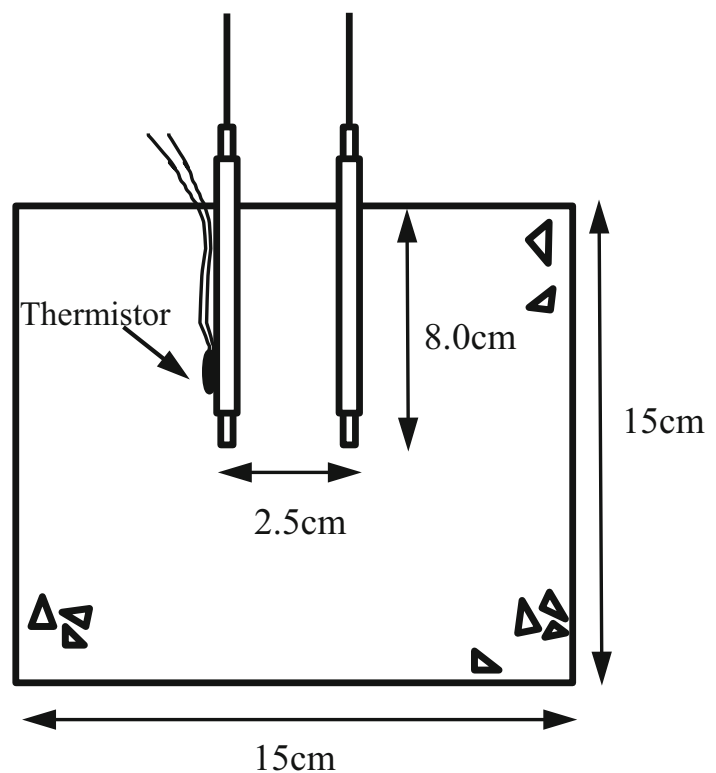

(a)

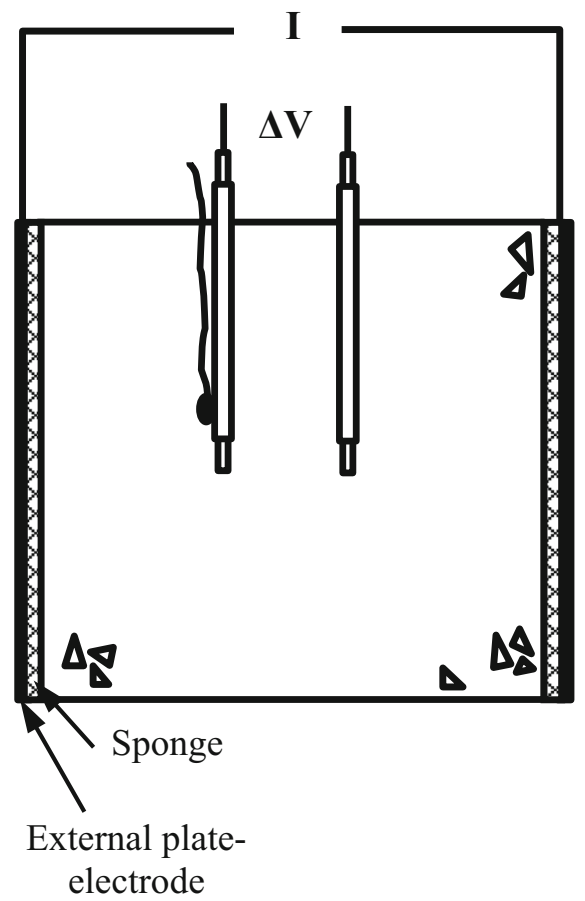

(b)

Fig. 1 a Positioning of electrodes and thermistor embedded within concrete specimens, and, $\mathbf{b}$ positioning of external plate electrodes for calibration purposes

(v) temperature reduced to $-30{ }^{\circ} \mathrm{C}$ at a rate of $6{ }^{\circ} \mathrm{C} / \mathrm{h}$;

(vi) steps (ii) to (iv), which forms one cycle, were repeated for 28 cycles.

Published rates for cooling $(-)$ and heating $(+)$ vary considerably ranging from $\pm 1.2 ;+4.1 /-3.3$; \pm 10 ; \pm 11 ; $\pm 15^{\circ} \mathrm{C} / \mathrm{h}[5,6,29-31]$ to more rapid rates of $\pm 24{ }^{\circ} \mathrm{C} / \mathrm{h}$

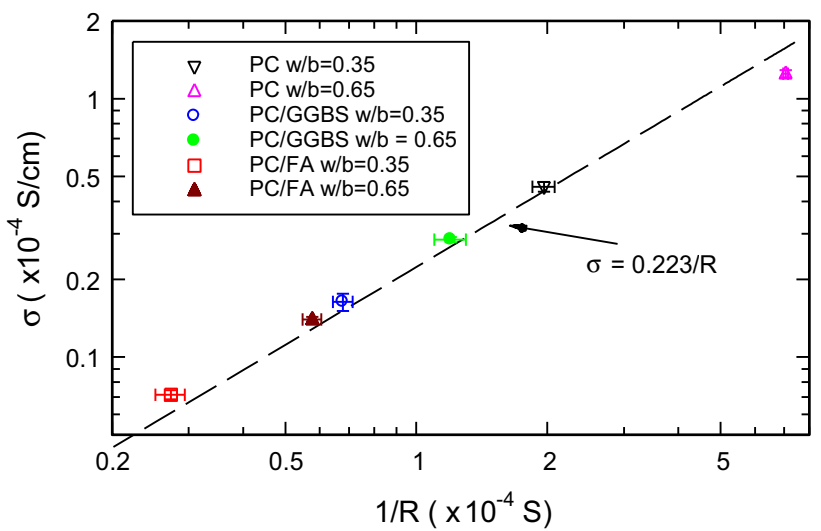

(a)

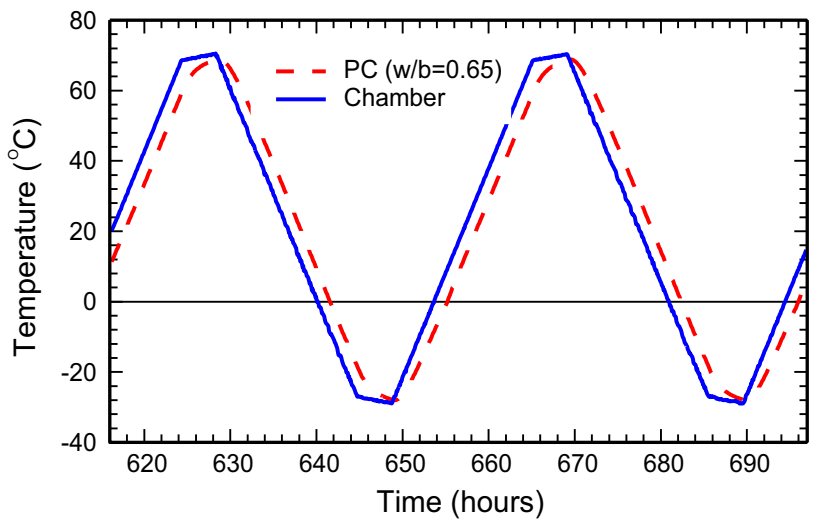

(b)

Fig. 2 a Calibration curve for embedded electrodes, and, b temperature of environmental chamber and internal temperature of specimen

[20] and $\pm 88{ }^{\circ} \mathrm{C} / \mathrm{h}$ [32] and ultra-rapid rates of $\pm 120{ }^{\circ} \mathrm{C} / \mathrm{h}$ [16] and $\pm 230{ }^{\circ} \mathrm{C} / \mathrm{h}$ [20]. The regime adopted was thus taken to represent a compromise.

For illustrative purposes, Fig. $2 b$ presents the chamber temperature and the temperature recorded at the centre of a concrete cube $(\mathrm{PC}$ mix with $\mathrm{w} / \mathrm{b}=0.65)$. The results show that there is a thermal lag of approximately $1.5 \mathrm{~h}$ which increases marginally at the upper and lower temperature extremes. The mass of the concrete cubes was monitored over the duration of the testing programme and was found to decrease by $\sim 0.05 \% /$ cycle (by mass of specimen) indicating some moisture loss from the surface of the samples.

\section{Results and discussion}

Conductivity measurements for the concrete mixes have been presented in an Arrhenius format, viz,

$\sigma=\sigma_{0} \mathrm{e}^{-\left[\frac{E_{a}}{R_{g} T}\right]}$

where $\sigma$ is the sample conductivity $(\mathrm{S} / \mathrm{cm})$ at temperature $T$ (Kelvin); $\sigma_{0}$ the pre-exponential factor and represents the 
nominal conductivity at infinite temperature; $E_{\mathrm{a}}$ is the activation energy for the conduction process $\left(\mathrm{J} \mathrm{mol}^{-1}\right)$ and $R_{g}$ is the Universal Gas constant $8.3141\left(\mathrm{~J} \mathrm{~mol}^{-1} \mathrm{~K}^{-1}\right)$. In the work discussed below, $\ln (\sigma)$ is plotted against $1000 /$ $T$ hence multiplying the slope of the plot by $R_{\mathrm{g}}$, obtains $E_{\mathrm{a}}$ in $\mathrm{kJ} \mathrm{mol}^{-1}$ which is the more usual unit (to convert activation energy in $\mathrm{kJ} \mathrm{mol}^{-1}$ to $\mathrm{eV} / \mathrm{ion}, E_{\mathrm{a}}$ should be divided by 96.485 ). The activation energy can be physically interpreted as the energy barrier that must be overcome for an ion to conduct and will be related to (for example) ionic level interactions and the macroscopic effect of ice formation.

Due to the considerable amount of data recorded over the test period, for illustrative purposes, curves are presented at the 7th and 28th cycles. Furthermore, whilst measurements were recorded every $5 \mathrm{~min}$ over the entire cyclic regime, for clarity, only selected points are highlighted on the Figures although the curves presented below are drawn through all measurement points.

\section{$\mathrm{PC}$ concretes}

Figure 3a displays the Arrhenius response for the PC concrete $\operatorname{mix}(\mathrm{w} / \mathrm{b}=0.35)$ presented over the entire temperature range $\left(+70\right.$ to $\left.-30^{\circ} \mathrm{C}\right)$ for the 7 th and 28 th cooling/heating cycles, with the direction of cooling/heating indicated. Regarding Fig. 3a, a linear relationship dominates the response for temperatures $>\sim 0{ }^{\circ} \mathrm{C}$ with the cooling and heating portions of the cycle being virtually coincident over an individual thermal cycle. This implies that the conduction process is reversible within this region. It is known that electrical conduction through saturated concrete occurs via ions in the continuous (percolated) aqueous phase between the electrodes [28]; since linearity exists over this portion of the thermal cycle, it implies that electrolytic conduction through the saturated pore network prevails within this region. It is also apparent from Fig. 3a that the conductivity of the concrete gradually decreases as the number of thermal cycles increases and results in a progressive downward displacement of the Arrhenius plot. This could, in part, be attributed to microstructural changes resulting from further hydration (being a thermally activated process [33, 34]); thermally induced changes in the existing hydration products which can occur above about $60{ }^{\circ} \mathrm{C}$ due to increased polymerization of the $\mathrm{C}-\mathrm{S}-\mathrm{H}$ gel phase [35] and possible shrinkage microcracking.

Considering the low-temperature end $\left(<\sim 0{ }^{\circ} \mathrm{C}\right)$ of a particular cycle as displayed in Fig. 3a, a change in gradient in the response is detected. The temperature at which this occurs depends on whether the sample is on the cooling (freezing) or heating (thawing) part of the thermal cycle. This has the effect of introducing hysteresis into the electrical conduction process in this region. Consider, for example, the

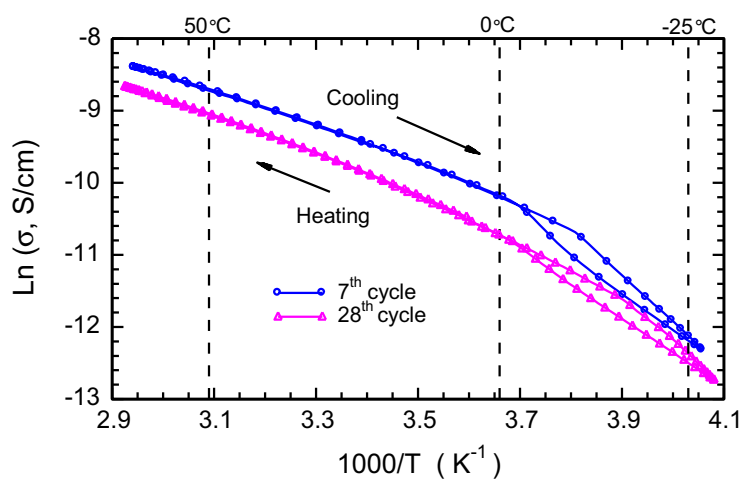

(a)

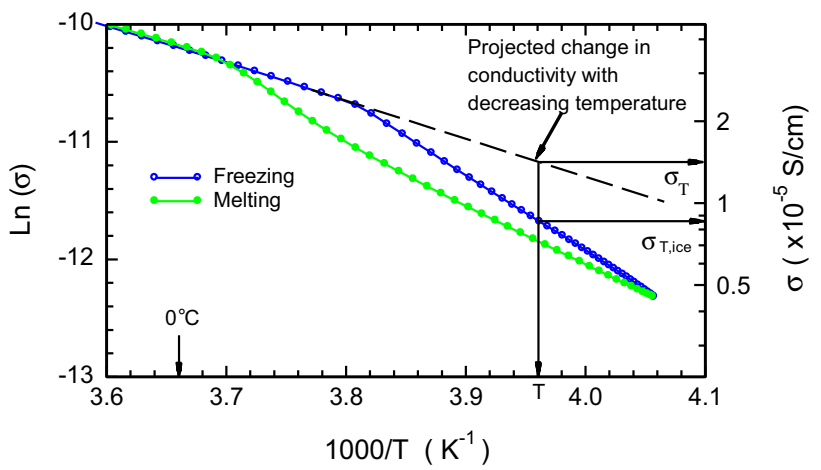

(b)

Fig. 3 Arrhenius plots for a PC concrete $(w / b=0.35)$ at 7 th and 28th cooling/heating cycle presented over the temperature range $+70 /-30^{\circ} \mathrm{C}$; b close-up of low-temperature end of Arrhenius plot during 7 th cycle

cooling portion of the curve on the 7th cycle presented in Fig. 3a, where a change in gradient is detected at approximately $-8.7^{\circ} \mathrm{C}$. The slope of the response over most of the temperature range (i.e. $+70 \rightarrow-8.7^{\circ} \mathrm{C}$ ) obtains an activation energy of, approximately, $22.6 \mathrm{~kJ} \mathrm{~mol}^{-1}$; over the remainder of the cooling cycle (i.e. $-8.7 \rightarrow-30{ }^{\circ} \mathrm{C}$ ) the activation energy is evaluated as $54.3 \mathrm{~kJ} \mathrm{~mol}^{-1}$. It could be inferred that the freezing point of the pore water within the pore network occurs at approximately $-8.7{ }^{\circ} \mathrm{C}$. Freezing results in a decrease in the volume of conductive pore fluid which, in turn, decreases the conductivity at a faster rate than the effect of decreasing temperature alone. As ice forms within the pore network, ionic concentrations within the unfrozen pore water must gradually increase; this would, in turn, increase its conductivity. It is evident, however, that the conductivity of the concrete decreases by more than an order of magnitude over the freezing portion of the cycle so it can be inferred that the decrease in conductivity due to the formation of ice in the pore network dominates over any increase in conductivity of the pore water due to increasing ionic concentration which would tend to increase the conductivity of the concrete.

Figure $3 \mathrm{a}$ also indicates that the conductivity increases monotonically during the thawing portion of the thermal 
cycle with a change in gradient occurring at approximately $-2.9^{\circ} \mathrm{C}$. The activation energy over the range $-30 \rightarrow$ $-2.9{ }^{\circ} \mathrm{C}$ is $46.0 \mathrm{~kJ} \mathrm{~mol}^{-1}$; at temperatures $>-2.9^{\circ} \mathrm{C}$, the heating curve 'joins' the cooling curve and has the same activation energy to the cooling curve viz. $22.6 \mathrm{~kJ} \mathrm{~mol}^{-1}$. The conductivity data in Fig. 3a also show that ice thaws at a higher temperature within the pore network than it forms; $-2.9{ }^{\circ} \mathrm{C}$ in the case of the former and $-8.7{ }^{\circ} \mathrm{C}$ for the latter. The hysteresis in conductivity could be explained by 'ink-bottle' effects whereby the pore network is regarded as comprising capillary cavities connected via finer capillary pore necks. During freezing, the phase transition in the pore network will be controlled by the radius of the constriction or pore neck as ice cannot intrude into larger capillary cavities until freezing is initiated in the pore neck whereas during thawing, ice in the pore neck will melt first.

Consider the freezing portion of the Arrhenius plot presented in Fig. 3b; if the decrease in conductivity was purely due to the decrease in temperature of the pore water without ice formation, then the Arrhenius plot would tend to follow the dashed line with an activation energy of $22.6 \mathrm{~kJ} \mathrm{~mol}^{-1}$. In this Figure, $\sigma_{T}$ represents the conductivity of the concrete at a given temperature, $T$, assuming no ice formed within the pore network and $\sigma_{T}$,ice represents the as-measured conductivity with ice formation. If, as a first approximation, it can be assumed that the conductivity of the concrete is proportional to the fractional volume of unfrozen pore water then the volumetric ratio of frozen pore water (commonly called the ice saturation ratio, $S_{\mathrm{c}}$ [3]) within the pore network could be estimated by the expression,

$S_{c}=\left(\frac{\sigma_{T}-\sigma_{T, \text { ice }}}{\sigma_{T}}\right)=\left(1-\frac{\sigma_{T, \text { ice }}}{\sigma_{T}}\right)$

At a given temperature, the data in Fig. $3 \mathrm{~b}$ indicate that the conductivity of the concrete is lower on the thawing portion of the cycle than it is on the freezing portion. Hence, from Eq. (4) above, more ice remains within the pore system on thawing than on freezing.

As the concrete undergoes thermal cycling, further changes in the Arrhenius plot are evident on the cooling, the temperature at which the gradient change, noted above, takes place decreases. On the 28th cycle, the gradient change on the cooling curve occurs at approximately $-15.4{ }^{\circ} \mathrm{C}$ giving respective values over the temperature range $+70 \rightarrow$ $-15.4^{\circ} \mathrm{C}$ of $24.5 \mathrm{~kJ} \mathrm{~mol}^{-1}$, and $53.0 \mathrm{~kJ} \mathrm{~mol}^{-1}$ over the range $-15.4 \rightarrow-30{ }^{\circ} \mathrm{C}$. Whilst the activation energy over the respective parts of the freezing curves presented in Fig. 3a remains relatively constant with thermal cycling, the freezing point depression of the pore fluid decreases from $-8.7^{\circ} \mathrm{C}$ on the 7 th cycle to $-15.4^{\circ} \mathrm{C}$ on the 28 th cycle. Considering the thawing portion of each cycle presented in Fig. $3 \mathrm{a}$, the gradient change on the 28 th cycle occurs at
Table 3 Summary of activation energy for all concrete mixes for temperatures $>\sim 0{ }^{\circ} \mathrm{C}$ on the heating (h) and cooling (c) portions of the thermal cycle

\begin{tabular}{lrrrr}
\hline Mix designation & w/b & \multicolumn{2}{l}{$\begin{array}{l}\text { Heating } \\
\text { (h):cooling(c) cycle }\end{array}$} & \multirow{2}{*}{$\sigma_{20} \times 10^{-5} \mathrm{~S} / \mathrm{cm}$} \\
\cline { 2 - 4 } & & \multicolumn{2}{c}{ 7th } & 28th \\
\hline PC & 0.35 & h\&c: 22.6 & 24.5 & 6.67 \\
& 0.65 & h\&c: 17.8 & 21.5 & 13.5 \\
PC/GGBS & 0.35 & h\&c: 27.9 & 28.6 & 1.50 \\
& 0.65 & c: 23.6 & c: 23.0 & 5.76 \\
PC/FA & 0.35 & h\&c: 29.8 & h: 21.2 & \\
& 0.65 & c: 26.7 & c: 26.2 & 1.15 \\
& & h: 26.0 & h: 24.2 \\
\end{tabular}

Also presented is the conductivity of the concrete, $\sigma_{20}$, prior to testing (at $20^{\circ} \mathrm{C}$ )

$-2.9^{\circ} \mathrm{C}$ remaining unchanged from the 7 th cycle. The activation energy evaluated over the temperature range $-30 \rightarrow-2.9^{\circ} \mathrm{C}$ on the 28 th cycle is $41.3 \mathrm{~kJ} \mathrm{~mol}^{-1}$ indicating a decrease with thermal cycling. The activation energy for conduction on the heating/cooling portions of each cycle over the temperature range +70 to $-30{ }^{\circ} \mathrm{C}$ is summarised in Tables 3 and 4 for the PC concretes.

The Arrhenius format of presentation allows evaluation of both the undercooling where thawing occurs (denoted $\Delta T_{\mathrm{t}}$ ) and undercooling where freezing occurs (denoted $\left.\Delta T_{\mathrm{f}}\right)$. The ratio $\Delta T_{\mathrm{t}} / \Delta T_{\mathrm{f}}$ is called the shape factor, $\lambda$, and is dependent on the radius of curvature of the ice-water meniscus during freezing and thawing [9, 36]. The shape factor provides information on the pore geometry but only if the freezing and thawing events occur in the same pore. A value $\lambda=1$ is expected for spherical pores i.e. freezing and thawing occur at the same temperature whereas a value of $\lambda=0.5$ occurs when ice melts in cylindrical pores [13, 34]. The shape factor will also be affected by the connectivity of the pores and generally falls in the range $0<\lambda \leq 1$ [9]. Table 4 presents the shape parameter, $\lambda$, for the PC mix presented in Fig. 3 where it has been assumed that freezing/thawing of the bulk liquid occurs at $0{ }^{\circ} \mathrm{C}$. It should be noted that ions in the pore water would reduce its freezing point below $0{ }^{\circ} \mathrm{C}$. Considering the ionic concentration in the pore water (primarily $\mathrm{Na}^{+}, \mathrm{K}^{+}, \mathrm{OH}^{-}$), it is estimated that the freezing point would lie between 0 and $-1{ }^{\circ} \mathrm{C}[37,38]$. For the purposes of this current study, a value of $0{ }^{\circ} \mathrm{C}$ is assumed. In all cases, $\lambda<0.5$ indicating a more complex pore structure than a simple spherical or cylindrical pore model can explain and other shapes may be required to explain this discrepancy (e.g. 'ink-bottle' effects noted above). 
Table 4 Summary of activation energy for PC; PC/GGBS; PC/ FA concrete mixes at the lowtemperature end $\left(<\sim 0{ }^{\circ} \mathrm{C}\right)$ of the Arrhenius plot; undercooling for freezing and thawing, and shape factor assuming that the freezing point of the bulk pore water is $0{ }^{\circ} \mathrm{C}$; estimated pore-neck $\left(r_{\mathrm{pn}}\right)$ and pore-cavity $\left(r_{\mathrm{pc}}\right)$ radii

\begin{tabular}{|c|c|c|c|c|c|c|c|}
\hline \multirow[t]{2}{*}{$\begin{array}{l}\text { Heating/cooling } \\
\text { cycle }\end{array}$} & \multicolumn{3}{|c|}{ Shape factor } & \multicolumn{2}{|c|}{$\begin{array}{l}\text { Activation } \\
\text { energy }\left(\mathrm{kJ} \mathrm{mol}^{-1}\right)\end{array}$} & \multicolumn{2}{|c|}{ Estimated pore radius (nm) } \\
\hline & $\Delta T_{\mathrm{f}}\left({ }^{\circ} \mathrm{C}\right)$ & $\Delta T_{\mathrm{t}}\left({ }^{\circ} \mathrm{C}\right)$ & $\lambda$ & Freezing & Thawing & Equation (6) $r_{\mathrm{pn}}$ & Equation (7) $r_{\mathrm{pc}}$ \\
\hline \multicolumn{8}{|c|}{$\mathrm{PC}$ concrete $(\mathrm{w} / \mathrm{b}=0.35)$} \\
\hline 7th & -8.7 & -2.9 & 0.33 & 54.3 & 46.0 & 8.0 & 11.8 \\
\hline 28th & -15.4 & -2.9 & 0.19 & 53.0 & 41.3 & 4.3 & 11.8 \\
\hline \multicolumn{8}{|c|}{$\mathrm{PC}$ concrete $(\mathrm{w} / \mathrm{b}=0.65)$} \\
\hline 7 th & -4.3 & -1.4 & 0.32 & 47.8 & 39.8 & 15.6 & 23.8 \\
\hline 28th & -10.0 & -2.9 & 0.29 & 35.8 & 28.5 & 7.0 & 11.8 \\
\hline \multicolumn{8}{|c|}{ PC/GGBS concrete $(w / b=0.65)$} \\
\hline 7th & -8.6 & -1.4 & 0.16 & 42.6 & 36.7 & 8.1 & 23.8 \\
\hline 28th & -10.7 & -1.4 & 0.13 & 42.9 & 37.8 & 6.7 & 23.8 \\
\hline \multicolumn{8}{|c|}{ PC/FA concrete $(\mathrm{w} / \mathrm{b}=0.65)$} \\
\hline 7th & -10.7 & -1.4 & 0.13 & 37.4 & 36.5 & 6.61 & 23.8 \\
\hline 28th & -15.4 & -2.1 & 0.14 & 34.0 & 34.0 & 4.77 & 16.1 \\
\hline
\end{tabular}

Regarding the undercooling during freezing/thawing, the Gibbs-Thompson equation allows the phase transition temperature of liquids in pores to be calculated, viz,

$\Delta T_{\mathrm{f}, \mathrm{t}}=T_{\mathrm{f}, \mathrm{t}}-T_{0}=-\frac{\gamma T_{0}}{\rho \eta} \frac{d A}{d V}$

where, $T_{\mathrm{f}, \mathrm{t}}$ is the phase transition temperature and the subscripts $f$ and $t$ refer to freezing or thawing, respectively (in Kelvin); $T_{0}$ is the normal melting point of ice and assumed to be $273.15 \mathrm{~K}\left(0{ }^{\circ} \mathrm{C}\right)$, hence $\Delta T_{\mathrm{f}, \mathrm{t}}=T_{f, t} ; \eta$ is the heat of fusion of ice per unit mass; $\rho$ is the density of water; $\gamma$ is the ice/water interfacial tension at temperature $T ; d A / d V$ is the curvature of the solid-liquid interface which is $1 / r$ for a cylindrical interface and $2 / r$ for a spherical interface and $\mathrm{r}$ is the radius of the curvature. $\Delta T_{\mathrm{f}, \mathrm{t}}$ represents the depression or undercooling of the freezing/ thawing point below the normal freezing/thawing point of ice. Based on the assumption that the ice-water interface adopts a spherical shape during freezing, the following expression for cement pastes has been presented to estimate the pore-neck radius, $r_{\mathrm{pn}}$ (in $\mathrm{nm}$, see Fig. 4 adapted from [39]), from the measured undercooling in freezing, $\Delta T_{\mathrm{f}}[9,13,14]$,

$r_{\mathrm{pn}}(\mathrm{nm})=-\frac{64.67}{\Delta T_{\mathrm{f}}}+0.57$

On the assumption that on thawing, ice melts from a cylindrical pore wall, the pore-cavity radius, $r_{\mathrm{pc}}$ (in $\mathrm{nm}$, see Fig. 4) can be estimated from the undercooling in thawing, $\Delta T_{t}[13,14]$,

$r_{\mathrm{pc}}(\mathrm{nm})=-\frac{32.33}{\Delta T_{t}}+0.68$

Equations (6) and (7) also assume that an unfrozen layer of water of thickness $0.8 \mathrm{~nm}$ lines the pore walls $[9,13]$.

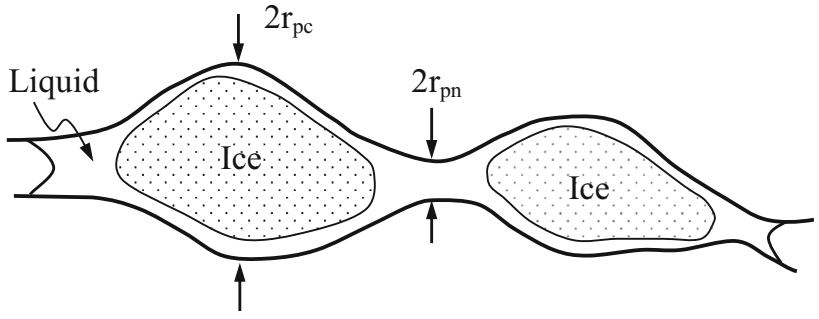

Fig. 4 Schematic representation of 'ink-well' model for capillary pore structure showing pore cavities (of diameter $2 r_{\mathrm{pc}}$ ) connected through pore necks (of diameter $2 r_{\mathrm{pn}}$ )

Using the data obtained for the PC concrete $(\mathrm{w} / \mathrm{b}=0.35)$ above, Table 4 presents the values for the radius of the pore neck and pore cavity evaluated from Eqs. (6) and (7). It must be stressed that these values represent, at best, an estimate as they must be considered with the inherent assumptions in Eqs. (6) and (7) and that the freezing point of bulk pore water is taken to be $0{ }^{\circ} \mathrm{C}$.

Figure 5 presents the results for the PC concrete with $\mathrm{w} / \mathrm{b}=0.65$ during the 7 th and 28 th cooling/heating cycles. Similar trends and features are observed, with the Arrhenius plot dominated by a linear response with the heating and cooling portions of the response being, as before, coincident, highlighting the reversible nature of the electrical conduction processes. Based on the linear portion of the response over the temperature range $+70 \leftrightarrow \sim 0{ }^{\circ} \mathrm{C}$ in Fig. 5, the activation energy on the 7 th and 28th cooling/ heating cycles, respectively, is presented in Table 2. Increasing the water-binder ratio not only results in an increase in conductivity of the concrete, but also there is a corresponding decrease in activation energy for conduction processes although, as with the PC concrete with $\mathrm{w} / \mathrm{b}=0.35$, the activation energy increases only 


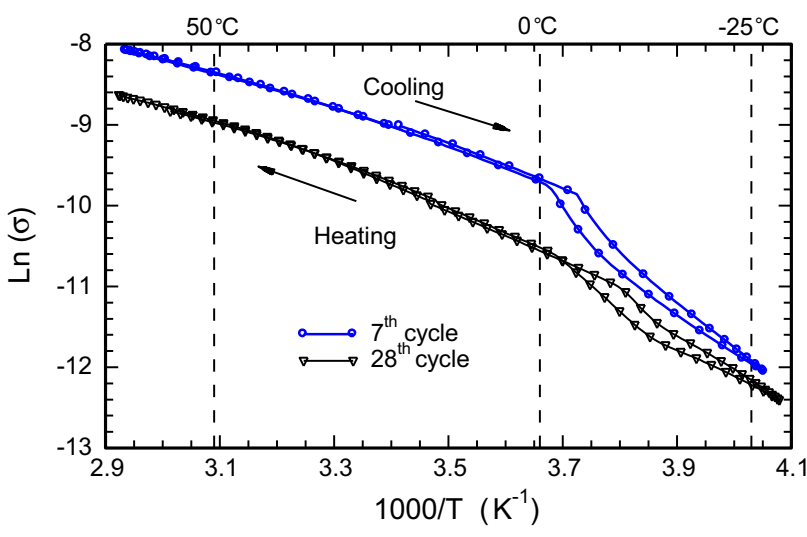

Fig. 5 Arrhenius plots for PC concrete $(w / b=0.65)$ at 7 th and 28th cooling/heating cycle presented over the temperature range $+70 /-$ $30{ }^{\circ} \mathrm{C}$

marginally with thermal cycling. The undercooling on the freezing and thawing portions of each cycle estimated from Fig. 5 are summarised in Table 4, together with the pore radii based on Eqs. (6) and (7) above. The activation energy estimated from these plots over the range $T_{\mathrm{f}} \rightarrow$ $-30{ }^{\circ} \mathrm{C}$ for freezing, and $-30{ }^{\circ} \mathrm{C} \rightarrow T_{t}$ for thawing, is also presented in Table 4.

\section{Concretes containing SCM's}

Figure 6 presents the Arrhenius plot for both the PC/GGBS concrete (Fig. 6a) and the PC/FA concrete (Fig. 6b) with $\mathrm{w} / \mathrm{b}=0.35$. In terms of absolute values, the conductivity of the PC/FA concrete is almost an order of magnitude lower than the PC/GGBS concrete and would result from a more disconnected and tortuous pore network. As with the PC concretes, there is an overall downward displacement of the Arrhenius plot with continued thermal cycling regime. The decrease in conductivity with thermal cycling is significantly less in the SCM concretes as compared to the PC concrete. As noted above, the changes could be due, in part, to heat treatment effects on the already formed products of hydration and if the SCM concretes have less change, it may indicate that the hydration products are more stable. It is interesting to note that there are no discernible hysteresis effects or abrupt changes in slope at the low-temperature end of the plot with the cooling/heating curves displaying a linear response. Furthermore, the heating and cooling responses indicate that the electrical conduction process is reversible over the entire temperature range. The activation energy for these concrete mixes is presented in Table 3. Figure 6 would suggest that the pore sizes within the concrete are such that the freezing point of the pore water has been reduced to less than $-30{ }^{\circ} \mathrm{C}$ and, from Eq. (6) above, this would imply a pore-neck radius $<\sim 3 \mathrm{~nm}$. Consider, again, Fig. 4 which presents a

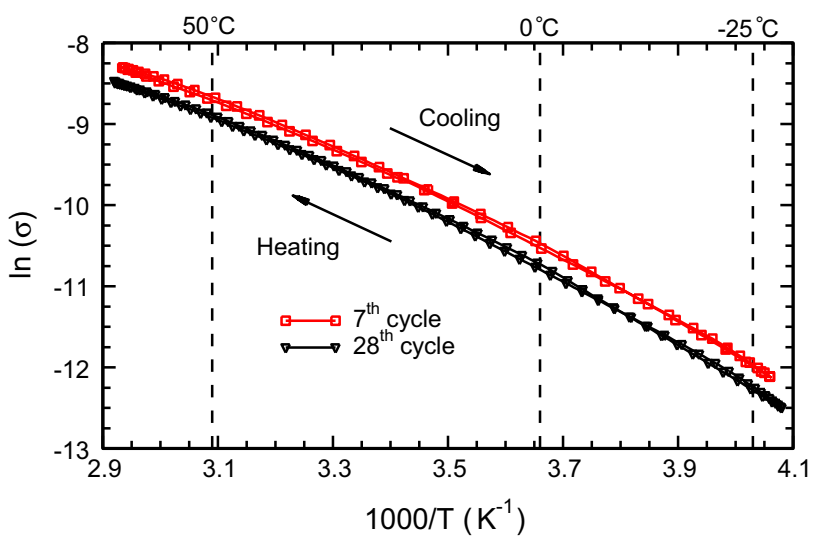

(a)

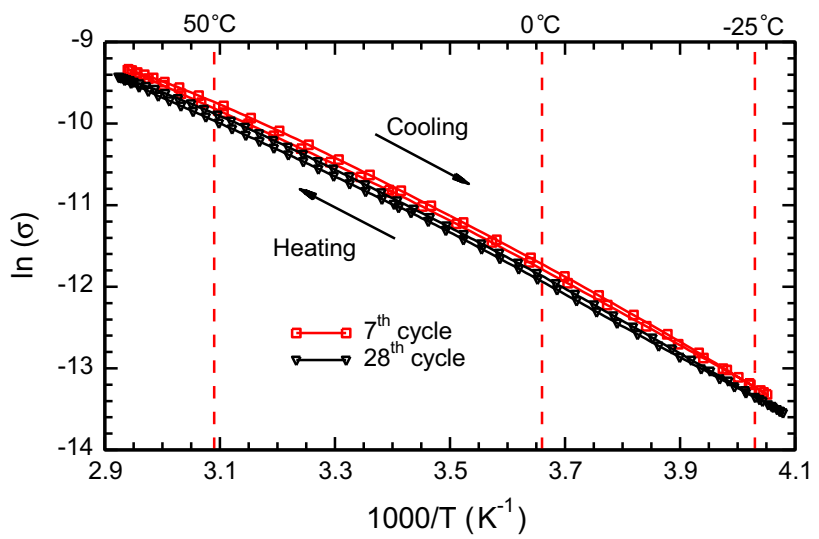

(b)

Fig. 6 Arrhenius plots for a GGBS/35 concrete $(w / b=0.65)$, and, b FA/35 concrete $(w / b=0.35)$ at 7 th and 28 th cooling/heating cycle presented over the temperature range $+70 /-30{ }^{\circ} \mathrm{C}$

schematic of the pore system; for ice to propagate from, say, left to right across the diagram, water must freeze in the pore neck before ice will form within the adjacent pore cavity. As ice formation will be controlled by the poreneck size, these concretes must have a finer pore entry size than the equivalent PC concrete in Fig. 3 which displays hysteresis.

The activation energy over the thermal cycling regime for the PC/GGBS and PC/FA concretes $(\mathrm{w} / \mathrm{b}=0.35)$ is presented in Table 3. When compared to the PC concrete, the higher activation energy and lower conductivity for these concretes would reflect further refinement to the microstructure. Figure 7 presents the Arrhenius response for the PC/GGBS concrete $(w / b=0.65)$. Based on the portion of the response over the temperature range $+70 \longleftrightarrow \sim 0{ }^{\circ} \mathrm{C}$, the activation energy for each heating/ cooling cycle is summarised in Table 3 . It is observed that the activation energy on heating is lower than on cooling and indicates hysteresis effects now exist in this temperature range with the concrete being more conductive on heating than on cooling. The difference between the 


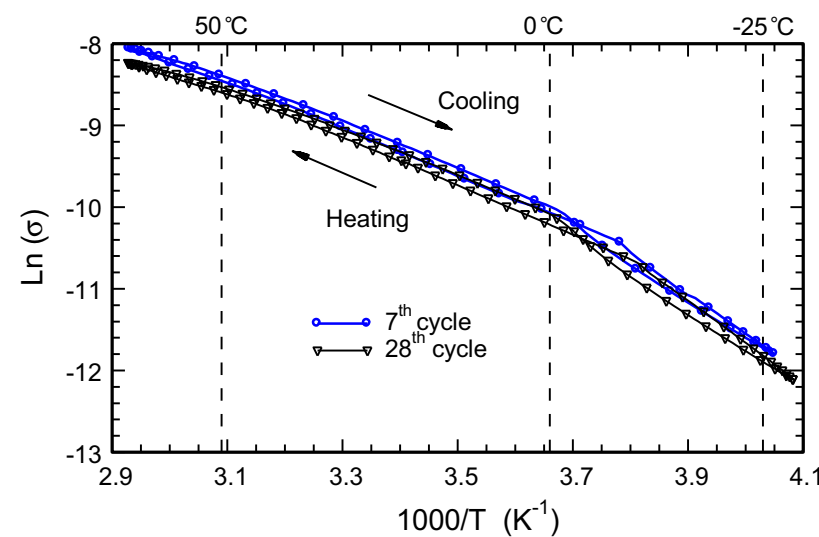

Fig. 7 Arrhenius plots for GGBS $/ 35$ concrete $(w / b=0.65)$ at 7 th and 28 th cooling/heating cycle over the temperature range +70 / $-30{ }^{\circ} \mathrm{C}$

conductivity value obtained on the heating portion and the cooling portion of the cycle (at the same temperature) increases with thermal cycling. This is further discussed below. Unlike the PC/GGBS concrete with $\mathrm{w} / \mathrm{b}=0.35$, Fig. 7 indicates that hysteresis effects are now present at the low-temperature end of the curves. This feature would be associated with microstructural differences in the pore network and the pore sizes are such that water can now freeze within them. Table 4 summarizes the activation energy and pore radii based using on the freezing and thawing point depression evaluated from Fig. 7. Again, it must be noted, Eqs. (6) and (7) have been developed on the assumptions that, upon cooling, the ice/water interface is assumed to be hemispherical, and on thawing, the interface is assumed to be cylindrical.

Figure 8 presents the Arrhenius plots for the fly ash concrete $(w / b=0.65)$. The activation energy is summarised in Table 4 for both the freezing and thawing portions of the response, together with the undercooling in freezing/ thawing and estimated pore radii. The data presented in Table 4 indicate that the PC/GGBS and PC/FA concrete $(\mathrm{w} / \mathrm{b}=0.65)$ has a pore structure comprising large pore cavities linked by fine pore necks. The pore-neck size will have a controlling influence on ice formation and propagation and would account for the fly ash concrete having a much reduced conductivity in comparison to the PC and PC/GGBS concretes. As with the PC concretes, at temperatures $<\sim 0{ }^{\circ} \mathrm{C}$, the conductivity of the PC/GGBS concrete and $\mathrm{PC} / \mathrm{FA}(\mathrm{w} / \mathrm{b}=0.65)$ is greater on the cooling portion of the response than the thawing portion indicating that more ice remains within the pore structure on thawing.

Closer examination of Figs. 7 and 8 shows that hysteresis effects are observed over virtually the entire heating/ cooling temperature cycle i.e. $+70 \longleftrightarrow-30{ }^{\circ} \mathrm{C}$, particularly in the case of the PC/FA concrete. This exemplified in

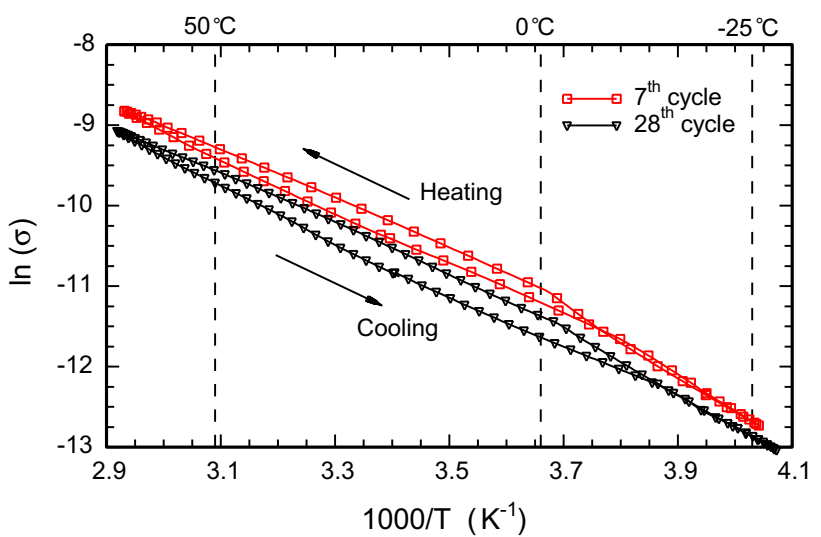

Fig. 8 Arrhenius plots for $F A / 35$ concrete $(w / b=0.65)$ at 7 th and 28th cooling/heating cycle presented over the temperature range $+70 /-30{ }^{\circ} \mathrm{C}$

Fig. 9 which presents the response on the 28th cooling/ heating cycle for both the PC/GGBS (Fig. 9a) and PC/FA (Fig. 9b) for $w / b=0.65$. These Figures indicate that the conductivity on the heating portion of the cycle is greater than on the cooling. In addition, the difference between these two portions of the response increases with thermal cycling and represents a behaviour which does not manifest itself in the other concretes. The emergence of more noticeable hysteresis effects could possibly be attributed to internal microcracking due to the heating and cooling regime as visual examination of the external surfaces of the specimens did not show any signs of damage. In addition to potential damage caused by ice formation on freezing, expansion of pore water on heating will cause the pore pressure in small pores to temporarily increase until internal diffusion equilibrates the pressure [40] and could result in another source of damage. The degree of damage will thus be related to the rate of heating and pore size distribution as the thermal expansion of water is confined pore spaces is greater than that of bulk water [41]. More work is continuing on this aspect although it is interesting to note that a similar hysteresis effect was observed in a more limited study on cement mortar prisms undergoing ultra-rapid heating/cooling cycles [20].

\section{Compressive strength, conductivity and activation} energy

With reference to Table 1 , the compressive strength of the concretes increases with time due to continuing hydration and pozzolanic reaction. It is also evident from Table 1 that at longer time scales the difference in strength between the PC, PC/GGBS and PC/FA concrete mixes (at a given w/b ratio) reduces. As the strength of concrete is strongly correlated with its porosity [42-45], this would indicate that 


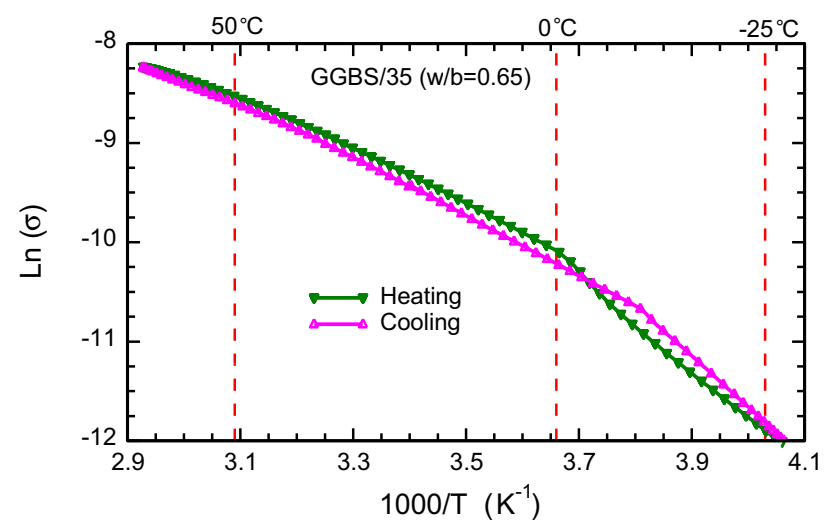

(a)

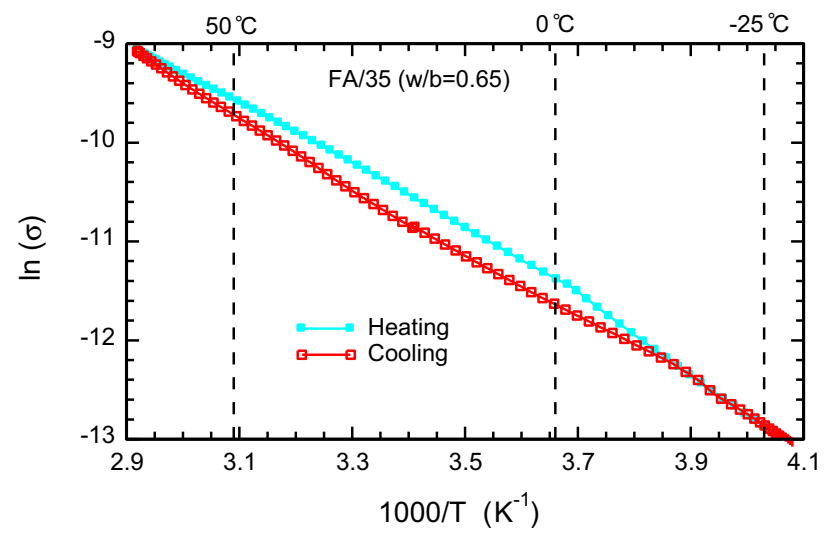

(b)

Fig. 9 Showing hysteresis in the Arrhenius plot (28th cycle) over the temperature range $+70 /-30{ }^{\circ} \mathrm{C}$ for a GGBS/35 concrete, and, b FA/ 35 concrete (both $\mathrm{w} / \mathrm{b}=0.65$ )

the concretes attain a similar overall porosity. It has been observed that although concretes containing SCM's are not of lower total porosity than PC concretes, they produce a more tortuous and disconnected capillary pore network [46, 47]. Table 3 presents the conductivity of the concrete mixes (denoted $\sigma_{20}$ ), obtained prior to the start of the thermal cycling. It is apparent that the conductivity values for the different mixes in Table 1 can vary by a factor of between three and four (at a given w/b ratio). In addition, low conductivity correlates with high activation energy and vice versa although, as with strength, the variation in activation energy between mixes is not as marked as their respective conductivity value.

As noted in section "PC concretes" above, electrical conduction through concrete will be primarily via the continuous, interstitial aqueous phase between the electrodes, hence conductivity will be dependent upon the continuous porosity which will, in turn, be related the pore tortuosity and pore constriction. These features, ultimately, determine properties such as the diffusivity and permeability of the concrete which are of importance in relation to concrete durability and performance [1]. A conductivity measurement may thus be more discriminating than strength in identifying durable concrete mixes and the methodology could be developed as a durability test method.

\section{Conclusions and concluding comments}

Electrical conductivity measurements have been presented on concretes undergoing thermal excursions over the extended temperature range $+70 /-30^{\circ} \mathrm{C}$. The Arrhenius format allowed estimation of the depression in freezing point and thawing point. From the study undertaken, the electrical conduction activation energy approach detailed could be exploited as a basis for development of novel concrete durability test methods and standards.

Although it has been assumed that the freezing point of 'bulk' pore water is $0{ }^{\circ} \mathrm{C}$ the following conclusions can be drawn from the current study:

Temperatures $>\sim 0{ }^{\circ} \mathrm{C}$

(1) A reduction in the $w / b$ ratio results in an increase in the activation energy for all concretes. It was observed that concretes containing SCM's have a higher activation energy that the plain PC concrete with the activation energy increasing in the order: PC/FA $>$ PC/GGBS $>$ PC at both w/b ratios and was attributable to microstructural differences in the pore network.

(2) For the PC concretes $(w / b=0.35$ and 0.65$)$ and concretes containing SCM's $(\mathrm{w} / \mathrm{b}=0.35)$, the activation energy on the heating and cooling portions of the response indicated that electrical conduction is reversible in this temperature range. For concretes containing SCM's $(\mathrm{w} / \mathrm{b}=0.65)$, the activation energy on cooling portion of the cycle was greater than that on the heating portion implying irreversible changes had taken place. This introduced hysteresis into the Arrhenius plot in this temperature range and attributed to microstructural damage caused by the cyclic heating/cooling regime.

Temperatures $<\sim 0{ }^{\circ} \mathrm{C}$

(3) The Arrhenius plots for the PC concretes (w/ $\mathrm{b}=0.35$ and 0.65 ) and concretes containing SCM's $(\mathrm{w} / \mathrm{b}=0.65)$ displayed significant hysteresis effects in this temperature range and attributed to freezing and thawing of the pore water. The Arrhenius plot indicated that the pore water freezes at a lower 
temperature that it melts. The freezing and thawing point of ice contained within the pore network was used to estimate the pore-neck and pore-cavity sizes and the values obtained suggested that the pore network comprised pore cavities connected through fine pore necks.

(4) Concretes containing SCM's at a w/b ratio of 0.35 displayed a linear response over the entire temperature range indicating that electrical conduction processes were reversible and that pore sizes were such that the water contained within them did not freeze.

(5) A simplified approach based on conductivity measurements was presented to estimate the volumetric ice fraction within the pore system which also showed that more ice remains with the pore system on thawing than on the freezing.

Acknowledgments Funding from the Engineering and Physical Sciences Research Council, UK (Research Grants EP/G025096, EP/ G02152X and EP/I005846) is gratefully acknowledged. The Authors also wish to acknowledge the technical support of AmphoraNDT (http://www.amphorandt.com).

\section{References}

1. Basheer PAM, Barbhuiya S (2010) Concrete durability: a practical guide to the design of durable concrete structures. In: Soutsos M (ed) Pore structure and transport processes. Thomas Telford, London

2. Cai H, Liu X (1998) Freeze-thaw durability of concrete: ice formation process in pores. Cem Concr Res 28(9):1281-1287

3. Fabbri A, Fen-Chong T, Azouni A, Thimus JF (2009) Investigation of water to ice phase change in porous media by ultrasonic and dielectric measurements. ASCE J Cold Reg Eng 23(2):6990

4. Li W, Pour-Ghaz M, Castro J, Weiss J (2012) Water absorption and critical degree of saturation relating to freeze-thaw damage in concrete pavement joints ASCE. J Mater Civ Eng 24(3):299-307

5. Bager DH, Sellevold EJ (1986) Ice formation in hardened cement paste, Part I: room temperature cured pastes with variable moisture contents. Cem Concr Res 16(5):709-720

6. Idem (1986) Ice formation in hardened cement paste, Part II: drying and resaturation on room temperature cured pastes. Ibid 16(6):835-844

7. Jacobsen S, Sellevold EJ, Matala S (1996) Frost durability of high strength concrete: effect of internal cracking on ice formation. Ibid 26(6):919-931

8. Sant G, Bentz D, Weiss J (2011) Capillary porosity depercolation in cement-based materials: measurement techniques and factors which influence their interpretation. Ibid 41(8):854-864

9. Sun Z, Scherer GW (2010) Pore size and shape in mortar by thermoporometry. Ibid 40(5):740-751

10. Jehng JY, Sprague DT, Halperin WP (1996) Pore structure of hydrating cement paste by magnetic resonance relaxation analysis and freezing. Magn Reson Imaging 14(7/8):785-791

11. Hansen EW, Gran HC, Sellevold EJ (1997) Heat of fusion and surface tension of solids confined in porous materials derived from a combined use of NMR and calorimetry. Am Chem Soc J Phys Chem B 101(35):7027-7032

12. Mitchell J, Beau J, Webber W, Strange JH (2008) Nuclear magnetic resonance cryoporometry. Phys Rep 461(1):1-36

13. Schulson EM, Swainson IP, Holden TM, Korhonen CJ (2000) Hexagonal ice in hardened cement. Cem Concr Res 30(2):191-196

14. Swainson P, Schulson EM (2001) A neutron diffraction study of ice and water within a hardened cement paste during freeze-thaw. Ibid 31(12): 1821-1830

15. Olson RA, Christensen BJ, Coverdale RT, Ford SJ, Moss GM, Jennings HM, Mason TO, Garboczi EJ (1995) Interpretation of the impedance spectroscopy of cement paste via computer modelling Part III: microstructural analysis of frozen cement paste. J Mater Sci 30(20):5078-5086. doi:10.1007/BF00356052

16. Perron S, Beaudoin JJ (2002) Freezing of water in Portland cement paste: an a.c. impedance spectroscopy study. Cem Concr Comp 24(5):467-475

17. Sato T, Beaudoin JJ (2011) Coupled AC impedance and thermomechanical analysis of freezing phenomena in cement paste. Mater Struct 44(2):405-411

18. Wang Z, Zeng Q, Wang L, Yao Y, Li K (2013) Characterizing blended cement pastes under cyclic freeze-thaw actions by electrical resistivity. Constr Build Mater 44(July):477-486

19. Idem (2014) Effect of moisture content on freeze-thaw behavior of cement paste by electrical resistance measurements. J Mater Sci 49(12):4305-4314. doi:10.1007/s10853-014-8126-2

20. Cao J, Chung DDL (2002) Damage evolution during freeze-thaw cycling of cement mortar studied by electrical resistivity measurement. Cem Concr Res 32(10):1657-1661

21. British Standards Institution BS-EN-197-1 (2000) Cement-part 1: composition, specifications and conformity criteria for common cements. BSI, London

22. British Standards Institution BS-EN15167-1 (2006) Ground granulated blast furnace slag for use in concrete, mortar and grout, part 1: definitions, specifications and conformity criteria. BSI, London

23. British Standards Institution BS-EN450-1 (2005) Fly ash for concrete-part 1: definition, specifications and conformity criteria. BSI, London

24. British Standards Institution BS-EN934-2 (2009) Admixtures for concrete, mortar and grout. Part 2: concrete admixtures. BSI, London

25. British Standards Institution BS 8500-1 (2006) Concrete- Complementary British Standard to BS EN 206-1, part 1: method of specifying and guidance for the specifer. BSI, London

26. McCarter WJ, Brousseau R (1990) The A.C. response of hardened cement paste. Cem Concr Res 20(6):891-900

27. McCarter WJ, Starrs G, Kandasami S, Jones MR, Chrisp M (2009) Electrode configurations for resistivity measurements on concrete. Am Concr Inst Mater J 106(3):258-264

28. Whittington HW, McCarter J, Forde MC (1981) The conduction of electricity through concrete. Mag Conc Res 33(114):48-60

29. Kjeldsen AM, Geiker MR (2008) On the interpretation of low temperature calorimetry data. Mater Struct 41(1):213-224

30. Setzer MJ, Fagerlund G, Janssen DJ (1996) CDF test: test method for the freeze-thaw resistance of concrete-tests with sodium chloride solution. Ibid 29(9):523-528

31. Basheer L, Cleland DJ (2006) Freeze-thaw resistance of concretes treated with pore liners. Constr Build Mater 20(10):990-998

32. American Society for Testing and Materials (ASTM) C666/ C666M-03 (2008) Standard test method for resistance of concrete to rapid freezing and thawing. In: Annual book of ASTM standards, vol 04.02. ASTM International, West Conshohocken, pp 341-346 
33. Schindler AK (2004) Effect of temperature on hydration of cementitious materials. Am Concr Inst Mater J 101(1):72-81

34. Lin F, Meyer C (2009) Hydration kinetics modeling of Portland cement considering the effects of curing temperature and applied pressure. Cem Concr Res 39(4):255-265

35. Thomas JJ, Jennings HM (2002) Effect of heat treatment on the pore structure and drying shrinkage behavior of hydrated cement paste. J Am Ceram Soc 85(9):2293-2298

36. Titulaer MK, Talsma H, Jansen JBH, Geus JW (1996) The formation of ice between hydrocalcite particles measured by thermoporometry. Clay Miner 31(2):263-277

37. Fagerlund G (1973) Determination of pore-size distribution from freezing-point depression. Mater Struct 6(33):191-201

38. Haghighi H, Chapoy A, Tohidi B (2008) Freezing point depression of electrolyte solutions: experimental measurements and modeling using the cubic-plus association equation of state. Ind Eng Chem Res 47(11):3983-3989

39. Zuber B, Marchand J (2000) Modeling the deterioration of hydrated cement systems exposed to frost action part 1: description of the mathematical model. Cem Concr Res 30(12):1929-1939

40. Ai H, Young JF, Scherer GW (2001) Thermal expansion kinetics: Method to measure permeability of cementitious materials: II application to hardened cement paste. J Am Ceram Soc 84(2):385-391
41. Xu S, Simmons GC, Scherer GW (2004) Thermal expansion and viscosity of confined liquids. Mat Res Soc Symp Proc 790:6.8.1-6.8.7 (MRS fall meeting symposium P: dynamics in small confining systems; Fourkas JT, Levitz P, Urbakh M, Wahl $\mathrm{KJ}$ (eds))

42. Claisse PA, Cabrera JG, Hunt DN (2001) Measurement of porosity as a predictor of the durability performance of concrete with and without condensed silica fume. Adv Cem Res 13(4): 165-174

43. Kumar R, Bhattacharjee B (2003) Porosity, pore size distribution and in situ strength of concrete. Cem Concr Res 33(1):155-164

44. Lian C, Zhuge Y, Beecham S (2011) The relationship between porosity and strength for porous concrete. Constr Build Mater 25(11):4294-4298

45. Chen X, Wu S, Zhou J (2013) Influence of porosity on compressive and tensile strength of cement mortar. Constr Build Mater 40(March):869-874

46. Li S, Roy DM (1986) Investigation of relations between porosity, pore structure, and $\mathrm{C}^{-}$diffusion of fly ash and blended cement pastes. Cem Concr Res 16(5):749-759

47. Lu S, Landis EN, Keane DT (2006) X-ray microtomographic studies of pore structure and permeability in Portland cement concrete. Mater Struct 39(6):611-620 